\title{
QUALIDADE DO LEITE CRU REFRIGERADO GRANELIZADO COLETADO NO SUDOESTE GOIANO
}

\section{Quality of raw milk refrigerated granelizado collected in southwest goiano}

\author{
Arthur Inácio Medeiros de França ${ }^{I}$, Marco Antônio Pereira da Silva ${ }^{*}$, \\ Julliane Carvalho Barros ${ }^{l}$, Marcos Roberto da Silva ${ }^{l}$, Rodrigo Balduíno Soares Neves ${ }^{l}$, \\ Luiz Eduardo Costa do Nascimento ${ }^{I}$, Edmar Soares Nicolau ${ }^{l}$
}

\begin{abstract}
RESUMO
Objetivou-se com o presente estudo avaliar a qualidade microbiológica e físico-química do leite em diferentes sistemas de produção, oriundos de produtores individuais e coletivos, da região de Rio Verde - GO. Foram coletadas amostras de leite cru refrigerado, armazenadas em tanques de expansão de propriedades rurais e tanques isotérmicos da região do sudoeste goiano. As amostras foram analisadas eletronicamente quanto a CCS (Contagem de Células Somáticas), composição centesimal e a CBT (Contagem Bacteriana Total). Foram realizadas 51 coletas de amostras de leite em tanques da propriedade rural, sendo 12 coletas de ordenha mecânica e 39 de ordenha manual; 13 em tanques de produtores coletivos e 38 de tanques individuais. Também foram coletadas 52 amostras de leite cru refrigerado (coleta 1), 15 amostras de leite granelizado que foram coletadas após o término da rota nas propriedades rurais (coleta 2) e 15 amostras de leite granelizado que foram coletadas após a chegada ao estabelecimento processador (coleta 3). Os resultados foram analisados, estatisticamente, pelo programa SISVAR por meio do teste de Tukey, ao nível de 5\% de significância. Em relação à composição centesimal, apenas o teor de gordura do leite cru refrigerado transportado a granel diferiu, significativamente, entre as coletas. Essa variação pode ter ocorrido devido ao procedimento de coleta das amostras, por uma possível falta de padrão da realização das mesmas. Os demais resultados não apresentaram diferença estatística, ao nível de 5\% de significância, de acordo com o teste utilizado. As condições de granelização
\end{abstract}

1 Instituto Federal Goiano, Campus Rio Verde, Rodovia Sul Goiana, Km 01, Zona Rural, s/n, 75901-970, Rio Verde, GO, Brasil. E-mail: marcotonyrv@yahoo.com.br

* Autor para correspondência.

Recebido / Received: 23/05/2016

Aprovado / Approved: 22/08/2016 
inadequadas do leite na fonte de produção influenciaram a qualidade microbiológica do leite, pois muitas amostras analisadas apresentaram contagens de CBT acima do permitido, de acordo com a legislação vigente. O leite ordenhado mecanicamente e oriundo de produtores individuais apresentaram CCS acima do limite estabelecido pela legislação brasileira. Medidas higiênico-sanitárias tomadas com mais critério são necessárias para que as características físico-químicas do leite sejam mantidas.

Palavras-chave: tanque isotérmico; tanque de expansão; armazenamento; CBT; CCS; composição centesimal.

\begin{abstract}
The present study aimed to evaluate the microbiological and physicochemical quality of milk in different production systems, producers arising from individual and collective, in the region of Rio Verde - GO. Samples were collected from refrigerated raw milk, stored in expansion tank farms and isothermal tanks of from the region of southwestern goiano. The samples were analyzed electronically regarding SCC, composition and TBC. We collected 51 samples of milk from farm tanks, 12 collections of milking machine and 39 of milking, 13 from tanks producers collective and 38 from individual tanks. We also collected 52 samples of raw milk refrigerated (Collection 1), 15 milk samples were collected granelizado after the end of route on farms (Collection 2) and 15 milk samples were collected granelizado after arrival at the dairy (Collection 3 ). The results were statistically analyzed by the SISVAR by Tukey test at $5 \%$ significance. In respect to composition only fat refrigerated raw milk transported in bulk differed significantly between samples, the variation may be due to the sampling procedure, the other results showed no statistical difference. Poor refrigeration granelizada milk production at the source resulted in CBT above allowed. The milk milked mechanically and come from individual producers resulted in SCC above the limit established by Brazilian legislation. Sanitary-hygienic measures taken more criteria are necessary to quality physico-chemical characteristics are maintained.
\end{abstract}

Keywords: tank isothermal; expansion tank; storage; TBC; SCC; chemical composition.

\section{INTRODUÇÃO}

A obtenção do leite de animais saudáveis, em condições higiênicas adequadas, e o seu resfriamento imediato a $4^{\circ} \mathrm{C}$ são medidas fundamentais e primárias para garantir a qualidade do leite e seus derivados (ARCURI et al., 2006).

A qualidade do leite cru é influenciada por múltiplos fatores, entre os quais se destacam os zootécnicos, associados ao manejo, a saúde da glândula mamária, alimentação e potencial genético dos rebanhos, além de outros fatores relacionados à obtenção e à armazenagem do leite recém-ordenhado (GUERREIRO et al., 2005).

Diante de diversas características que interferem nas características do leite, o sistema de ordenha e coleta são de extrema importância, por ter relação direta com as informações sobre os parâmetros físico-químicos e segurança alimentar da cadeia produtiva do leite.

Além da escolha do melhor manejo, 
deve-se prezar pela estocagem sob refrigeração do leite na propriedade rural e transporte até as indústrias de laticínios, conforme previsto na IN 62 (BRASIL, 2011). Para Santos et al. (2009) com a granelização do leite na propriedade rural, a produção passou a ser entregue a qualquer hora do dia, já que os tanques de expansão garantem a qualidade do leite por até 48 horas.

O Ministério da Agricultura, Pecuária e Abastecimento (MAPA), com o objetivo de melhorar a qualidade do leite no País, regulamentou a Instrução Normativa 51 (IN 51), em 18 de setembro de 2002 (BRASIL, 2002). De acordo com essas normas, o leite deveria ser refrigerado na propriedade rural e apresentar um padrão de qualidade. No entanto, diante do cenário do setor laticinista apresentado desde a sua implementação, em 2011, essa normativa foi substituída e complementada pela Instrução Normativa 62 (IN 62) de 29 de dezembro de 2011 (BRASIL, 2011) para que a cadeia produtiva pudesse fornecer um produto de melhor qualidade para o consumidor e possibilitar aos produtores se adequarem às exigências estabelecidas e fornecerem leite de qualidade microbiológica dentro dos limites regulamentados.

A coleta a granel é realizada em caminhões isotérmicos, em dias alternados, e vem substituindo gradativamente a coleta em latões, de modo a modernizar e agilizar a recepção da matéria prima pelas indústrias, gerando economia de mão de obra e transporte, bem como diminuindo as perdas por acidificação do leite (SOUZA et al., 2009). Esse processo gera economia de mão-deobra e transporte. Entretanto, o processo de granelização, embora tenha se tornado cada vez mais popular e racionalize o processo de captação do leite, apresenta questões muito preocupantes que influenciam diretamente a qualidade do leite cru refrigerado.

Martins et al. (2013) ao avaliar a qualidade microbiológica e físico-química de amostras de leite cru constatou haver uma elevada ocorrência de alta CBT em tanques de expansão coletivos, fazendo necessário o desenvolvimento de medidas preventivas para diminuir esse problema.

Reis et al. (2007) afirmaram que a coleta de amostras de leite individual deve ser criteriosa, para que essas possam refletir a sua real composição, de acordo, com diferentes tipos de ordenha (manual ou mecânica) e metodologias de coleta, poderiam ocorrer variações nos teores dos seus componentes, produzindo resultados desiguais na análise laboratorial de uma mesma amostra de leite.

Diante do exposto, o presente estudo teve como objetivo, avaliar a qualidade do leite em diferentes sistemas de produção, oriundos de produtores individuais e coletivos, da região de Rio Verde - GO.

\section{MATERIAL E MÉTODOS}

\section{Amostragem}

Foram coletadas amostras de leite cru refrigerado, armazenadas em tanques de expansão de propriedades rurais e tanques isotérmicos da região do sudoeste goiano Goiás, fornecedoras de leite a uma indústria de laticínio, localizada em Rio Verde - GO.

O laticínio responsável pela coleta granelizada recebia e processava aproximadamente, $30 \mathrm{mil} \mathrm{L/dia} \mathrm{durante} \mathrm{o} \mathrm{período} \mathrm{estu-}$ dado. O laticínio era devidamente registrado no Serviço de Inspeção Federal (SIF) para a fabricação de queijo mussarela, prato, ricota e manteiga.

Os tanques de expansão instalados nas propriedades rurais possuíam capacidade de armazenamento de aproximadamente $1.000 \mathrm{~L}$ a $4.000 \mathrm{~L}$ e os caminhões que realizavam a coleta granelizada possuíam tanques isotérmicos de capacidade de aproximadamente $8.500 \mathrm{~L}$ a $9.000 \mathrm{~L}$.

As amostras foram coletadas em condições assépticas, após a agitação mecânica 
programada no próprio tanque de expansão, logo após a chegada do carro tanque isotérmico à propriedade rural. As coletas das amostras de leite foram realizadas em frascos contendo conservante bronopol ${ }^{\circledR}$ para análise de CCS e composição centesimal e azidiol $^{\circledR}$ para análise de CBT, onde foram acondicionadas em caixa isotérmica contendo gelo e encaminhadas ao Laboratório de Qualidade do Leite do Centro de Pesquisa em Alimentos da Escola de Veterinária e Zootecnia da Universidade Federal de Goiás em Goiânia, para a realização das análises eletrônicas.

Foram realizadas 51 coletas de amostras de leite em tanques da propriedade rural, sendo doze coletas de ordenha mecânica e trinta e nove de ordenha manual; treze coletas feitas de tanques de produtores coletivos e trinta e oito de tanques individuais. Também foram coletadas 52 amostras de leite cru refrigerado (coleta 1), 15 amostras de leite granelizado que foram coletadas após o término da rota nas propriedades rurais (coleta 2) e 15 amostras de leite granelizado que foram coletadas após a chegada ao laticínio (coleta 3).

\section{Análises físico-químicas}

As análises de composição centesimal foram realizadas em relação aos teores de: gordura, proteína, lactose, extrato seco total (EST) e extrato seco desengordurado (ESD) foram determinados através do princípio analítico que baseia-se na absorção diferencial de ondas infravermelhas pelos componentes do leite, utilizando-se o equipamento Milkoscan 4000 (Foss Electric A/S. Hillerod, Denmark). As amostras foram previamente aquecidas em banho maria à temperatura de $40^{\circ} \mathrm{C}$ por 15 minutos para dissolução da gordura. Os resultados foram expressos em porcentagem $(\%)$.

\section{Contagem de Células Somáticas}

A análise de células somáticas (CS) foi realizada de acordo com princípio analítico que se baseia na citometria de fluxo realizada através do equipamento Fossomatic 5000 Basic (Foss Electric A/S. Hillerod, Denmark). Antes da análise, as amostras foram previamente aquecidas em banho-maria à temperatura de $40^{\circ} \mathrm{C}$ por 15 minutos para dissolução da gordura. Os resultados foram expressos em $\mathrm{CS} / \mathrm{mL}$.

\section{Contagem Bacteriana Total}

A contagem bacteriana total (CBT) foi realizada por meio do equipamento Bactoscan FC (Foss Eletric A/S. Hillerod, Denmark), baseia-se na citometria de fluxo que consiste na medição de características celulares, quando estas se encontram suspensas em meio fluido. Os resultados foram expressos em $\mathrm{UFC} / \mathrm{mL}$.

\section{Análises Estatísticas}

A análise estatística foi realizada através do programa SISVAR (FERREIRA, 2003). Para comparação dos valores médios encontrados para a composição centesimal, CCS e CBT, em relação aos diferentes tipos de ordenha (manual e mecânica), produtor (individual e coletivo) e para as análises físico-químicas e células somáticas nas diferentes coletas, utilizou-se o teste de Tukey ao nível de 5\% de significância.

Para avaliar a evolução da CBT durante o transporte nas três diferentes coletas, os resultados foram expressos na função $\log$, com o uso de recursos do Excel versão 2007.

\section{RESULTADOS E DISCUSSÃO}

Na Tabela 1 são apresentados os resultados da composição e contagens bacterianas 
do leite cru refrigerado dos diferentes tipos de ordenha manual e mecânica das propriedades rurais.

Os teores de gordura, proteína, lactose e EST não diferiram em relação à ordenha manual e mecânica. Quanto ao ESD, houve diferença significativa entre os diferentes tipos de ordenha. Os produtores que obtinham leite através da ordenha manual apresentaram maior percentual na composição centesimal em comparação à ordenha mecânica, com exceção da gordura que os valores foram iguais. Esta diferença pode ser explicada pelo fato de se tratar de análises de diferentes propriedades, cada qual com manejo alimentar distinto.

A legislação brasileira IN/62 (BRASIL, 2011), estabelece que os sólidos não gordurosos do leite, sejam no mínimo de 8,4\%; mínimos de 3,0\% para gordura; mínimo de $2,9 \%$ de proteína e EST de $11,4 \%$. Na presente pesquisa, os resultados mostraram estar dentro dos padrões para amostras de leite com ordenha manual e ordenha mecânica.

Netto et al. (2009) comparando a qualidade do leite em ordenha manual e mecânica, verificaram que os resultados obtidos para a composição não sofreram alteração, o que justificaram pelo manejo dos animais serem semelhante ao longo do experimento. Diferentemente do observado na presente pesquisa, houve diferença estatística no ESD entre os diferentes tipos de ordenha, talvez essa diferença seja devida dieta fornecida aos animais.

Houve diferença significativa entre ordenha manual e mecânica, na determinação de CCS, conforme apresentado na Tabela 1 . É possível notar que amostras de leite obtidas de produtores com ordenha mecânica apresentaram alta contagem de células somáticas, $972 \mathrm{mil} \mathrm{CS} / \mathrm{ml}$, estando fora dos padrões da IN 62. Já as amostras de leite obtidas de produtores com ordenha manual apresentaram valores de $457 \mathrm{mil} \mathrm{CS} / \mathrm{mL}$, estando dentro da normativa em questão, ou seja, com um máximo de $500 \mathrm{mil} \mathrm{CS} / \mathrm{mL}$.

Apesar dos avanços apresentados pelo Brasil em relação à qualidade microbiológica do leite, principalmente após a implementação da nova legislação para o setor lácteo, problemas relacionados às infecções nas glândulas mamárias das vacas em produção resultam em leite refrigerado com altos valores de células

Tabela 1 - Resultados médios da gordura, proteína, lactose, EST, ESD, CCS, e CBT do leite cru refrigerado obtido por meio da ordenha manual ou mecânica em propriedades leiteiras

\begin{tabular}{cccc}
\hline \multirow{2}{*}{ Parâmetros } & \multicolumn{2}{c}{ Tipo de ordenha } & CV (\%) \\
\cline { 2 - 3 } & Manual $(\mathrm{n}=39)$ & Mecânica $(\mathrm{n}=12)$ & \\
\hline Gordura (\%) & $3,00^{\mathrm{ns}}$ & $3,00^{\mathrm{ns}}$ & 6,67 \\
Proteína (\%) & $3,05^{\mathrm{ns}}$ & $3,00^{\mathrm{ns}}$ & 6,42 \\
Lactose (\%) & $4,75^{\mathrm{ns}}$ & $4,58^{\mathrm{ns}}$ & 9,69 \\
EST (\%) & $12,07^{\mathrm{ns}}$ & $11,83^{\mathrm{ns}}$ & 4,47 \\
ESD (\%) & $8,90^{\mathrm{a}}$ & $8,58^{\mathrm{b}}$ & 4,09 \\
CCS (x1000 CS/mL) & $457^{\mathrm{b}}(2,56 \log )$ & $972^{\mathrm{a}}(2,86 \log )$ & 11,99 \\
CBT(x1000 UFC/mL) & $3948^{\mathrm{ns}}(2,86 \log )$ & $5215^{\mathrm{ns}}(3,29 \log )$ & 27,08 \\
\hline
\end{tabular}

Médias seguidas de letras distintas na linha diferem estatisticamente entre si $(\mathrm{P}<0,05)$. EST $=$ extrato seco total. $\mathrm{ESD}=$ extrato seco desengordurado. $\mathrm{CCS}=$ contagem de células somáticas. $\mathrm{CBT}=$ contagem bacteriana total. $\mathrm{ns}=$ não significativo $(\mathrm{P}>0,05)$. 
somáticas que, consequentemente, promovem modificações na composição físico-química do produto com diminuição de sua qualidade e vida útil e de seus derivados.

$\mathrm{Na}$ pesquisa realizada na região central do Paraná em propriedades com ordenha mecânica, a média encontrada foi de 621.224 CS/mL (VALLIN et al., 2009). Gonzalez et al. (2003), ainda relatam que o estresse provocado pelo tempo de contenção das vacas, o tempo decorrido entre a desinfecção do úbere e a colocação de teteiras e os bezerros ao pé da vaca, entre outros fatores, seriam efetivamente os responsáveis pela maior predisposição às mastites, dessa forma elevando a CCS.

Para as análises de CBT, entre as amostras de leite obtidas da ordenha manual e mecânica, não houve diferença estatística (ao nível de 5\%). No entanto, as amostras de leite ordenhadas mecanicamente apresentaram maior contaminação por bactérias (5.215.000 UFC/mL) em comparação com a ordenha manual (3.948.000 UFC/mL), mas todos os diferentes tipos de ordenha estão fora do recomendado pela legislação (máximo $300 \mathrm{mil} \mathrm{UFC/mL).}$
Diferentemente do encontrado na presente pesquisa, Lima et al. (2006), em seu trabalho verificaram que as contagens bacterianas, foram mais elevadas em propriedades com ordenha manual $\left(3,2 \times 10^{8} \mathrm{UFC} / \mathrm{mL}\right)$ em relação a ordenha mecânica $\left(1,6 \times 10^{7}\right.$ $\mathrm{UFC} / \mathrm{mL}$ ), indicando falhas higiênicas no manejo de ordenha, mas ambas estavam fora do padrões o que se faz necessário a introdução de um programa de educação sanitária, junto aos produtores e beneficiadores do leite para melhorar a qualidade do produto e seus derivados.

Os resultados das amostras de leite cru refrigerado obtidos de produtores individuais e coletivos estão dispostos na Tabela 2.

Avaliando as amostras de leite em relação aos tipos de produtor individual e coletivo (Tabela 2), observa-se que não houve diferença significativa quanto os parâmetros físico-químicos, CCS e CBT avaliados. Igualmente, aos diferentes tipos de ordenha (manual e mecânica) para a composição centesimal, os diferentes produtores de leite individual e coletivo, estavam de acordo com as exigências da legislação brasileira. Para os teores de gordura que apresentaram iguais

Tabela 2 - Resultados médios da composição e contagens bacterianas do leite refrigerado obtido de produtores individuais e coletivos em propriedades leiteiras da região de Rio Verde, GO

\begin{tabular}{cccc}
\hline \multirow{2}{*}{ Parâmetros } & \multicolumn{2}{c}{ Tipo de produtor } & CV (\%) \\
\cline { 2 - 3 } & Individual $(\mathrm{n}=38)$ & Coletivo $(\mathrm{n}=13)$ & \\
\hline Gordura (\%) & $3,00^{\mathrm{ns}}$ & $3,00^{\mathrm{ns}}$ & 6,73 \\
Proteína (\%) & $3,05^{\mathrm{ns}}$ & $3,00^{\mathrm{ns}}$ & 6,47 \\
Lactose (\%) & $4,76^{\mathrm{ns}}$ & $4,53^{\mathrm{ns}}$ & 9,65 \\
EST (\%) & $12,07^{\mathrm{ns}}$ & $11,84^{\mathrm{ns}}$ & 4,52 \\
ESD (\%) & $8,86^{\mathrm{a}}$ & $8,69^{\mathrm{b}}$ & 4,23 \\
CCS (x1000 CS/mL) & $644^{\mathrm{ns}}(2,66 \log )$ & $401^{\mathrm{a}}(2,55 \log )$ & 12,87 \\
CBT(x1000 UFC/mL) & $4043^{\mathrm{ns}}(2,90 \log )$ & $4840^{\mathrm{ns}}(3,19 \log )$ & 27,42 \\
\hline
\end{tabular}

Médias seguidas de letras distintas na linha diferem estatisticamente entre si $(\mathrm{P}<0,05)$. EST $=$ extrato seco total. $\mathrm{ESD}=$ extrato seco desengordurado. $\mathrm{CCS}=$ contagem de células somáticas. $\mathrm{CBT}=$ contagem bacteriana total. $\mathrm{ns}=$ não significativo $(\mathrm{P}>0,05)$. 
para os diferentes produtores, as amostras de leite individual foram maiores que as amostras de leite coletivo.

Souza et al. (2011) avaliando 9 propriedades rurais, observaram que apenas o valor do teor de gordura obtido nas amostras da propriedade 8 apresentou-se fora dos padrões legais e que as amostras de leite de conjunto analisadas durante o experimento apresentaram-se de acordo com o proposto pela legislação (IN 62), para os requisitos físico-químicos.

A partir dos valores obtidos para contagem de células somáticas foi possível observar que as amostras dos produtores individuais (644 $\mathrm{mil} \mathrm{CS} / \mathrm{mL}$ ), esteve fora dos padrões recomendado pela IN 62, com contagem máxima de $500 \mathrm{mil} \mathrm{CS} / \mathrm{mL}$ (BRASIL, 2011). A alta contagem de células somáticas promove modificações na composição físico-química do produto com diminuição de sua qualidade e vida útil e de seus derivados.

Os resultados da CBT para produtores individuais (4043 $\mathrm{mil} \mathrm{UFC/mL)} \mathrm{e} \mathrm{coletivos}$ (4840 mil UFC/mL) foram maiores que os permitidos pela legislação brasileira que admite o recebimento de leite com até 300 $\mathrm{mil} \mathrm{UFC/mL}$.
Martins et al., (2008) verificaram trinta tanques de expansão, onde nove estavam com CBT acima de $10^{6} \mathrm{UFC} / \mathrm{mL}$ (coletivo), quatorze (individual) estavam entre $10^{5}$ e $10^{6} \mathrm{UFC} / \mathrm{mL}$ e sete (individual) estavam abaixo de $10^{5} \mathrm{UFC} / \mathrm{mL}$.

Os valores médios e coeficiente de variação da composição centesimal e CCS do leite em diferentes coletas estão apresentados na Tabela 3.

O teor de gordura do leite cru refrigerado transportado a granel diferiu significativamente entre as coletas. Foi possível observar que houve um aumento do teor de gordura desde a propriedade até a chegada a indústria. A variação do percentual de gordura pode ter ocorrido devido ao procedimento de coleta das amostras. Porém, os resultados indicaram que nas diferentes coletas as amostras de leite cru refrigerado estavam de acordo com a legislação brasileira (BRASIL, 2011), que permite o recebimento de leite com teor mínimo de gordura de 3,0\%.

Os resultados da proteína bruta, lactose, EST, ESD e CCS não diferiram significativamente durante o trajeto e todos os valores estão dentro dos padrões exigidos pela legislação. Esses resultados eram esperados, pois a rota de coleta do leite granelizado

Tabela 3 - Resultados médios da qualidade do leite durante o transporte granelizado

\begin{tabular}{ccccc}
\hline \multirow{2}{*}{ Parâmetros } & \multicolumn{3}{c}{ Coletas } & \multirow{2}{*}{ CV $(\%)$} \\
\cline { 2 - 4 } & 1 & 2 & 3 & 8,38 \\
\hline Gordura (\%) & $3,37^{\mathrm{b}}$ & $3,44^{\mathrm{ab}}$ & $3,59^{\mathrm{a}}$ & 3,65 \\
Proteína (\%) & $3,23^{\mathrm{ns}}$ & $3,22^{\mathrm{ns}}$ & $3,23^{\mathrm{ns}}$ & 3,97 \\
Lactose (\%) & $4,52^{\mathrm{ns}}$ & $4,49^{\mathrm{ns}}$ & $4,50^{\mathrm{ns}}$ & 3,51 \\
EST (\%) & $12,08^{\mathrm{ns}}$ & $12,11^{\mathrm{ns}}$ & $12,27^{\mathrm{ns}}$ & 2,95 \\
ESD (\%) & $8,70^{\mathrm{ns}}$ & $8,67^{\mathrm{ns}}$ & $8,69^{\mathrm{ns}}$ & 10,97 \\
CCS (x1000 CS/mL) & $576^{\mathrm{ns}}$ & $508^{\mathrm{ns}}$ & $562^{\mathrm{ns}}$ & 1050 \\
\hline
\end{tabular}

Médias seguidas de letras distintas na linha diferem estatisticamente entre si $(\mathrm{P}<0,05)$. EST $=$ extrato seco total. ESD = extrato seco desengordurado. $\mathrm{CCS}=$ contagem de células somáticas. ns $=$ não significativo $(\mathrm{P}>0,05)$. 
não possibilitaria alterações na composição centesimal e CCS durante um curto percurso entre as propriedades rurais e a indústria beneficiadora.

Em estudos relatados por Silva et al. (2009), a CCS não diferiu entre os períodos do ano e tipos de amostra, ou seja, o transporte a granel do leite cru refrigerado obtido na propriedade rural e transportado até o laticínio não afetou a CCS do leite.

Martins et al. (2013), ao analisarem amostras de leite cru refrigerado, constataram que $25,7 \%$ das amostras avaliadas estavam próprias para o processamento ao detectarem média geral de $106 \mathrm{UFC/mL}$ para os microrganismos mesófilos aeróbios. Valores de $510.000 \mathrm{CS} / \mathrm{mL}$ em amostras de leite refrigerado em tanques de expansão, valor de acordo com o padrão da IN 62 também foram reportados por estes autores.

Avaliado os resultados para CBT na presente pesquisa, foi possível verificar que durante o transporte das amostras de leite houve alta contagem bacteriana, resultado da falta de refrigeração adequada. A Figura 1 demonstra a evolução da CBT durante o transporte granelizado do leite.

$\mathrm{O}$ crescimento bacteriano expresso em $\log \mathrm{UFC} / \mathrm{mL}$ (Figura 1) resultou em regressão linear significativa $\left(\mathrm{R}^{2}=99,73 \%\right)$ demonstrando que ocorreu contaminação do leite granelizado oriunda das más condições higiênico-sanitárias de obtenção do leite, da falta de higiene do tanque isotérmico e ausência de refrigeração do leite durante o transporte.

Para Mattioda et al. (2011), o leite deve ser armazenado, o mais rápido possível, em temperaturas adequadas para inibir o crescimento microbiano, pois a refrigeração não corrige falhas de higiene durante a ordenha.

Estes resultados tanto para as diferentes ordenhas, produtores e coletas, evidenciaram a necessidade da implantação de práticas de higiene no manejo e estocagem, visando à diminuição da CBT do leite e garantia maior segurança aos consumidores.

Para Vallin et al., (2009) a adoção de boas práticas de higiene na ordenha durante a pesquisa contribuíram significativamente para a melhoria da qualidade do leite em quaisquer das condições de tecnificação estudadas (ordenha manual ou mecânica). Embora a CBT não tenha diferido significativamente na presente pesquisa, entre os tipos de leite avaliados, a falta de manutenção dos refrigeradores pode ter contribuído para o aumento de microrganismos do leite.

\section{CONCLUSÕES}

A má refrigeração do leite na fonte de produção resultou em CBT acima do permitido

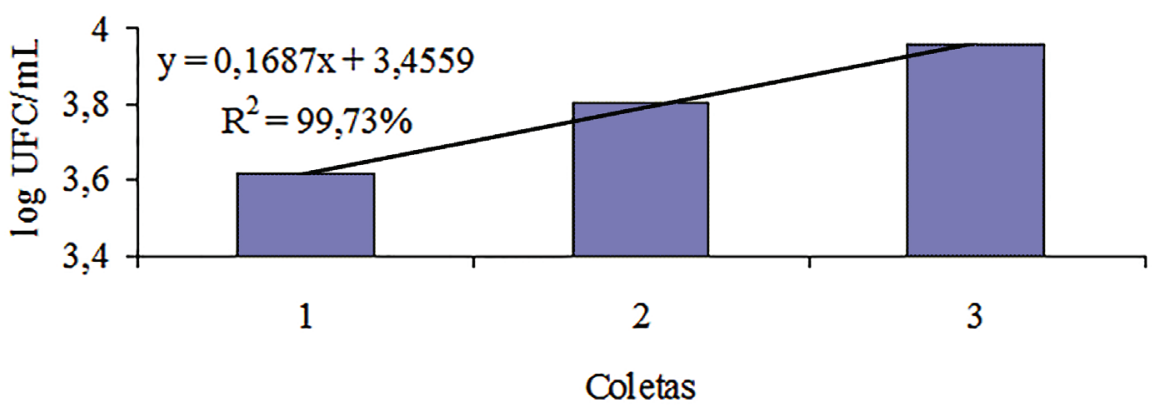

Figura 1 - Evolução da contagem bacteriana total durante o transporte do leite cru refrigerado 
pela legislação brasileira. As possíveis causas para esta ocorrência seriam a falta de rigor na verificação da temperatura de estocagem do leite, bem como má manutenção dos tanques de expansão. Medidas que visem diminuir a contagem bacteriana durante a estocagem na propriedade rural e transporte são eficazes e imprescindíveis para a produção de leite cru de qualidade microbiológica satisfatória e que não comprometa o processamento de seus derivados.

O leite ordenhado mecanicamente e oriundo de produtores individuais apresentou valores de CCS acima do limite estabelecido pela legislação brasileira, podendo estar relacionado com possíveis lesões ocorridas nos tetos devido a calibração incorreta do equipamento, além da ocorrência de leite residual. Desta forma, medidas higiênico-sanitárias e de manejo sanitário são necessárias para evitar a incidência de mastite clínica e subclínica no leite cru e que a características físico-químicas do mesmo não sejam afetadas para não diminuir, consequentemente, sua qualidade e a vida útil de seus derivados.

\section{REFERÊNCIAS}

ARCURI, E. F. et al.; Qualidade microbiológica do leite refrigerado nas fazendas. Arquivo Brasileiro de Medicina Veterinária e Zootecnia, v. 58, n. 3, p. 440-446, 2006.

BRASIL. Ministério da Agricultura, Pecuária e Abastecimento. Instrução Normativa $n^{\circ} 62$, de 29 de dezembro de 2011. Aprova o Regulamento Técnico de Produção, Identidade e Qualidade do Leite tipo A, o Regulamento Técnico de Identidade e Qualidade de Leite Cru Refrigerado, o Regulamento Técnico de Identidade e Qualidade de Leite Pasteurizado e o Regulamento Técnico da Coleta de Leite Cru Refrigerado e seu Transporte a Granel, em conformidade com os Anexos desta Instrução Normativa. Diário Oficial da República
Federativa do Brasil, Brasília, 30 dez. 2011. Seção 1, p. 6.

BRASIL. Ministério da Agricultura, Pecuária e Abastecimento. Departamento de Inspeção de Produtos de Origem Animal. Instrução Normativa $n^{\circ} 51$, de 18 de setembro de 2002. Aprova os Regulamentos Técnicos de Produção, Identidade e Qualidade do Leite tipo A, do Leite tipo B, do Leite tipo C, do Leite Pasteurizado e do Leite Cru Refrigerado e o Regulamento Técnico da Coleta de Leite Cru Refrigerado e seu Transporte a Granel, em conformidade com os Anexos a esta Instrução Normativa. Diário Oficial da República Federativa do Brasil, Brasília, 20 set. 2002. Seção 1, p. 8-13.

\section{EXCEL. Microsoft Office 2007. 2007.}

FERREIRA, D. F. Sisvar: versão 4.3 (Build 43). Lavras: Departamento de Ciências Exatas, Universidade Federal de Lavras, 2003.

GONZALEZ, S. G. et al. Influência de fatores raciais e manejo nutricional na contagem de células somáticas e nos constituintes do leite de vacas holandesas e mestiças no Norte do estado do Paraná, Brasil. Acta Scientiarum, Paraná, v. 25, n. 2, p. 323-329, 2003.

GUERREIRO, P. K. et al. Qualidade microbiológica de leite em função de técnicas profiláticas no manejo de produção. Ciência e Agrotecnologia, v. 29, n. 1, p. 216-222, 2005.

LIMA, M. C. G. et al. Contagem de células somáticas e análises físico-químicas e microbiológicas do leite cru tipo c produzido na região agreste do estado de Pernambuco. Arquivos do Instituto Biologico, v. 73, n. 1, p. 89-95, 2006.

MARTINS, M. E. P. et al. Qualidade de leite 
cru produzido e armazenado em tanques de expansão no estado de Goiás. Ciência Animal Brasileira, v. 9, n. 4, p. 1152-1158, 2008 .

MARTINS, M. L. et al. Qualidade do leite cru dos tanques de expansão individuais e coletivos de um laticínio do município de Rio Pomba, MG - Um estudo de caso. Revista do Instituto de Laticínios Cândido Tostes, v. 68 , n. 392, p. 24-32, 2013.

MATTIODA, F. et al. Qualidade do leite de pequenas propriedades rurais de Fernandes Pinheiro e Teixeira Soares - PR. Revista ADMpg Gestão Estratégica, Paraná, v. 4, n. 1, 2011.

NETTO, A. S. et al.; Estudo comparativo da qualidade do leite em ordenha manual e mecânica. Revista do Instituto de Ciências da Saúde, v. 27, n. 4, p. 345-349, 2009.

REIS, G. L. et al. Procedimentos de coleta de leite cru individual e sua relação com a composição físico-química e a contagem de células somáticas. Ciência Rural, v. 37, n. 4, p. 1134-1138, 2007.
SANTOS, P. A. et al. Efeito do tempo e da temperatura de refrigeração no desenvolvimento de microrganismos psicrotróficos em leite cru refrigerado coletado na macrorregião de Goiânia, GO. Ciência Animal Brasileira, v. 10, n. 4, p. 1237-1245, 2009.

SILVA, M. A. P. et al. Influência do transporte a granel na qualidade do leite cru refrigerado. Revista do Instituto Adolfo Lutz, São Paulo - São Paulo, v. 68, n. 3, 2009.

SOUZA, V. et al. Características microbiológicas de amostras de leite de tanque comunitário. Arquivo Brasileiro de Medicina Veterinária e Zootecnia, v. 61, n. 3, p. 758-761, 2009.

SOUZA, V. et al. Características físico-químicas de amostras de leite de tanque comunitário. Ciência Animal Brasileira, v. 12, n. 1, p. 144-148, 2011.

VALLIN, V. M. et al. Melhoria da qualidade do leite a partir da implantação de boas práticas de higiene na ordenha em 19 municípios da região central do Paraná. Semina: Ciências Agrárias, v. 30, n. 1, p. 181-188, 2009. 